\title{
Information Packaging: From Cards To Boxes
}

\author{
Herman Hendriks \\ OTS, Utrecht University
}

In his work on information packaging-i.e., the structuring of propositional content in function of the speaker's assumptions about the hearer's information stateVallduví $(1992,1993,1994)$ identifies the informational primitives focus, link and tail, which are adapted from the traditional focus/ground and topic/comment approaches, and argues that the exploitation of information states of hearers by the information-packaging strategies of speakers reveals that these states have at least the internal structure of a system of Heimian file cards: links, which correspond to what are traditionally known as topics, say where-on what file card-the focal information goes, and tails indicate how it fits there. Since there are various reasons for not believing this, the present paper proposes to model information states as Kampian discourse representation structures, without locations. This requires and leads to a different perspective on the function of links. They signal non-monotone anaphora: their discourse referent $\mathrm{Y}$ is anaphoric to an antecedent discourse marker $\mathrm{X}$ such that $\mathrm{X} \nsubseteq \mathrm{Y}$. This idea will be shown to subsume 'non-identity' anaphora, contrastive stress, pronoun referent resolution, and restrictiveness of relatives and adjectives.

\section{Information Packaging}

The notion of information packaging is introduced in Chafe (1976):

[The phenomena at issue] have to do primarily with how the message is sent and only secondarily with the message itself, just as the packaging of toothpaste can affect sales in partial independence of the quality of the tooth paste inside. (Chafe 1976: 28)

The basic idea is that speakers do not present information in an unstructured way, but that they provide a hearer with detailed instructions on how to manipulate and integrate this information according to their beliefs about the hearer's knowledge and attentional state:

To ensure reasonably efficient communication, $[\ldots \mathrm{t}]$ he speaker tries, to the best of his ability, to make the structure of his utterances congruent with his knowledge of the listener's mental world. (Clark and Haviland 1977: 5)

On all levels the crucial factor appears to be the tailoring of an utterance by a sender to meet the particular assumed needs of the intended receiver. 
That is, information packaging in natural languge reflects the sender's hypotheses about the receiver's assumptions and beliefs and strategies. (Prince 1981: 224)

For instance, sentences such as (1) and (2) are truth-conditionally equivalent in that they express the same proposition, but each of them 'packages' this proposition in a prosodically different way: ${ }^{1}$

\section{(1) The boss hates BROCCOLI}

\section{(2) The boss HATES broccoli}

Typically, speakers will use (1) if the hearer at the time of utterance knows nothing about or is not attending to the boss' relation to broccoli, while they will use (2) if the hearer at the time of utterance knows that there exists a relation between the boss and broccoli, is attending to this relation, but does not know what it is. Apparently, speakers are sensitive to such differences in the hearer's knowledge and attentional state, and hearers rely on this:

speakers not using this device systematically give their listeners a harder time. (Nooteboom and Terken 1982: 317)

Truth-conditionally equivalent sentences encoding different information packaging instructions are not mutually interchangeable salva felicitate in a given context of utterance: for example, of the above sentences, only the first one is a felicitous answer to the question What does the boss hate? It is this context-sensitivity that has traditionally placed information packaging within the realm of pragmatics.

Vallduvi's account of information packaging $(1992,1993,1994)$ is a combination of two influential earlier pragmatic approaches, the 'topic/comment' approach and the 'focus/ground' approach.

According to the focus/ground approach, sentences consist of a 'focus' and a 'ground'. ${ }^{2}$ The focus is the informative part of the sentence, the part that (the speaker believes) makes some contribution to the hearer's mental state. The ground is the non-informative part of the sentence, the part that anchors the sentence to what is already established or under discussion in (the speaker's picture of) the hearer's mental state. Although sentences may lack a ground altogether, sentences without focus do not exist.

The topic/comment approach splits the set of subexpressions of a sentence into a 'topic', the-typically sentence-initial-part that expresses what the sentence is about, and a 'comment', the part that expresses what is said about the topic. Topics are points of departure for what the sentence conveys, they link it to previous discourse. Sentences may be topicless: so-called 'presentational' or 'news' sentences consist entirely of a comment.

In Reinhart (1982), it is argued that the dimension of 'old'/'new' information is irrelevant for the analysis of sentence topics. Instead, the notion of 'pragmatic 
aboutness' is is defined in terms of the organization of information. The set of Possible Pragmatic Assertions that can be made with a sentence $S$ expressing proposition $\varphi$ is defined as $\operatorname{PPA}_{(\mathbf{S})}=\{\varphi\} \cup\left\{\langle a, \varphi\rangle \mid a\right.$ is the interpretation of an NP in $\left.\mathbf{S}^{3}\right\} \mathrm{A}$ pragmatic assertion $\langle a, \varphi\rangle$ is assumed to be about the NP interpretation $a$.

Notice, by way of example (adopted from Dahl 1974), that the sentence The boss hates BROCCOLI gives rise to the parallel topic/comment and ground/focus partitions indicated in (3) if it answers the questions What about the boss? What does he feel?, whereas it induces the partitions specified by (4) in the interrogative context What about the boss? What does he hate?

\begin{tabular}{|c|c|}
\hline topic & \multicolumn{2}{|c|}{ comment } \\
\hline The boss & hates BROCCOLI \\
\hline ground & focus \\
\hline
\end{tabular}

\begin{tabular}{|c|c|c|}
\hline topic & \multicolumn{2}{c|}{ comment } \\
\hline The boss & hates & BROCCOLI \\
\hline \multicolumn{2}{|c|}{ ground } & focus \\
\hline
\end{tabular}

The fact that the two informational articulations correspond to different partitions in (4) shows that neither of them is by itself capable of capturing all the informational distinctions present in the sentence. Therefore, Vallduvi proposes to conflate the two traditional binomial articulations of focus/ground and topic/comment into a single trinomial and hierarchical one. The core distinction is the one between new information and anchoring, between focus and ground. In addition, the ground is further divided into the 'link', which corresponds approximately to the topic in the traditional topic/comment approach, ${ }^{4}$ and the 'tail'. ${ }^{5}$ In a picture:

\begin{tabular}{|c|c|c|}
\hline topic & \multicolumn{2}{|c|}{ comment } \\
\hline link & tail & focus \\
\hline \multicolumn{2}{|c|}{ ground } & focus \\
\hline
\end{tabular}

Given this articulation, the answer The boss hates BROCCOLI to the questions What about the boss? What does he hate? will receive the following analysis:

\begin{tabular}{|c|c|c|}
\hline The boss & hates & BROCCOLI \\
\hline link & tail & focus \\
\hline \multicolumn{2}{|c|}{ ground } & focus \\
\hline
\end{tabular}

Roughly speaking, the different parts-focus and ground, link and tail-of a sentence $S$ have the following informational functions.

The focus encodes $I_{S}$, the information of $S$, which can be metaphorically described as $C_{S}$, the proposition expressed by $S$, minus $K_{\mathrm{h}}$, the information (the speaker presumes) already present in the hearer's information state.

The ground performs an ushering role-it specifies the way in which $I_{\mathrm{S}}$ fits in the hearer's information state: links indicate where $I_{S}$ should go by denoting a location in the hearer's information state, and tails indicate how $I_{\mathrm{S}}$ fits there by 
signaling a certain mode of information update. Of course, talking about ushering information to some location in the hearer's information state presupposes that this information state has some sort of internal structure. In this respect, Vallduví purports to

agree with Heim that there has to be some additional internal structure in the hearer's model of the common ground that plays an important role in natural language interpretation, even if this internal structure is of tangential relevance in truth value computation. It is this internal structure of information states which is, in fact, crucially exploited by the different information-packaging strategies used by speakers in pursuing communicative efficiency. (Vallduví 1994: 7)

\section{From Cards ...}

In fact, Vallduví takes the metaphor of Heim's file change semantics $(1982,1983)$ literally, in that he assumes that the information in the hearer's model is organized in files, i.e., collections of file cards. Each file card represents a discourse entity: its attributes and its links with other discourse entities are recorded on the card in the form of conditions. Such a discourse entity may be known to the hearer but not salient at the time of utterance, it may be salient at the time of utterance, it may be completely new to the hearer, it may be inferable from what the hearer knows, etc. Discourse entities mediate between referring expressions (noun phrases) and entities in the real world: indefinite noun phrases prompt hearers to create a new file card, and definite noun phrases incite them to retrieve an already existing file card. Both definites and pronouns denote already existing file cards, but pronouns denote salient file cards, whereas (other) definites refer to non-salient ones.

File change comprises the above aspects of file card management, but it also involves content update, i.e., the incorporation of information conveyed by a given sentence into records on novel and familiar file cards, and this is where Vallduví lets information packaging come in.

Links are associated with so-called GOTO instructions. In file change semantics, the target location of such a declaration is a file card $f_{r}$. A tail points at an information record-normally a (possibly underspecified) condition-on such a file card, $\operatorname{RECORD}(f c)$, and indicates that it has to be modified (or further specified) by the focus information $I_{S}$ of the sentence. The associated instruction type is called UPDATE-REPLACE. In the absence of a tail, the focus information $I_{\mathrm{S}}$ of a sentence is simply added at the current location. The associated instruction type is called UPDATE-ADD.

Sentences may lack links and tails (recall that the focus is the only non-op- 
tional part of a sentence), so the following four sentence types can be distinguished:
a. link-focus
b. focus
c. focus-tail
d. link-focus-tail

The above sentence types are associated with the following (compound) instruction types, respectively:
a. $\operatorname{GOTO}(f c)\left(\mathrm{UPDATE}-\mathrm{ADD}\left(I_{\mathrm{S}}\right)\right)$
b. UPDATE-ADD $\left(I_{S}\right)$
c. UPDATE-REPLACE $\left(I_{S}, \operatorname{RECORD}(f c)\right)$
d. $\operatorname{GOTO}(f c)\left(\operatorname{UPDATE}-\operatorname{REPLACE}\left(I_{S}, \operatorname{RECORD}(f c)\right)\right)$

The sentence and instruction types in (7) and (8) can be illustrated with the following examples, where links, tails and foci are specified by means of $[\mathrm{L} . .],.[\mathrm{T} .$.$] and [\mathrm{F} \ldots]$ brackets, respectively, and accented expressions in foci and links are-as abovewritten in small caps (representing $\mathrm{H}^{*}$ pitch accent) and boldface (for $\mathrm{L}+\mathrm{H}^{*}$ pitch accent), respectively:

$$
\begin{aligned}
& \text { a. link-focus: [ [LThe boss][Fhates BROCCOLI] } \\
& \operatorname{GOTO}(f c)\left(\text { UPDATE-ADD }\left(I_{S}\right)\right) \\
& \text { b. focus: [ } \quad[\mathrm{F} \text { He always eats BEANS] } \\
& \text { UPDATE-ADD }\left(I_{\mathrm{S}}\right) \\
& \text { c focus-tail: } \quad\left[{ }_{\mathrm{F}} \mathrm{He}\right. \text { is NOT][Tdead] } \\
& \text { UPDATE-REPLACE }\left(I_{S}, \operatorname{RECORD}(f c)\right) \\
& \text { d. link-focus-tail: [LThe boss][FHATES][T broccoli] } \\
& \left.\operatorname{GOTO}(f c) \text { (UPDATE-REPLACE }\left(I_{\mathrm{S}}, \operatorname{RECORD}(f c)\right)\right)
\end{aligned}
$$

As regards the first example, suppose that a newly appointed temp is ordering dinner for the boss and asks the executive secretary whether there is anything that should known about the boss' taste. The executive secretary gives the following answer:

\section{[LThe boss] $[$ Fhates BROCCOLI]}

Example (10) is a link-focus construction, and as such it is therefore associated with a GOTO $(f c)\left(\right.$ UPDATE-ADD $\left(I_{S}\right)$ ) instruction. The link subject the boss specifies a locus of update $f($, viz., the card representing the boss - card \#25, say. The focus verb phrase hates broccoli specifies the information $I_{S}$ that has to be added to this card. Suppose that broccoli is represented by card \#136. Then, passng over some formal details, the UPDATE-ADD $\left(I_{S}\right)$ instruction associated with the focus hates broccoli amounts to adding the condition 'hates $(25,136)$ ' to the locus of update, i.e., the boss' card $\# 25$. Moreover, the record ' $\mapsto 25$ ', a pointer to the locus of update, is added to card \#136, rendering the condition 'hates $(25,136)$ ' on card \#25 'accessible' from card \#136: Vallduví says that this linking mechanism, which designates a unique 
location for content update, is 'much more efficient' than straightforward multiple recording of information on cards.

\begin{tabular}{|c|c|c|c|c|}
\hline 25 & 136 & & 25 & 136 \\
\hline $\operatorname{boss}(25)$ & broccoli(136) & $\Rightarrow$ & $\begin{array}{l}\operatorname{boss}(25) \\
\text { hate }(25,136)\end{array}$ & $\begin{array}{l}\text { broccoli(136) } \\
\mapsto 25\end{array}$ \\
\hline
\end{tabular}

(11) [FHe always eats BEANS]

All-focus example (11) is associated with a simple UPDATE-ADD $\left(I_{S}\right)$ instruction. Here, this instruction involves the addition of the focus information $I_{S}$ that the value of the current card always eats beans. That is: if it is interpreted immediately after example (10) and if we leave its adverbially modified transitive verb phrase unanalyzed for simplicity, it amounts to adding the condition 'always eats beans(25)' to card $\# 25$.

The presence of a tail in a sentence signals a mode of update different from the straightforward UPDATE-ADD $\left(I_{\mathbf{S}}\right)$ instruction. A tail indicates that a (possibly underspecified) record on a file card has to be replaced (or specified further). The material in the tail serves the purpose of determining which record. Suppose, for example, that (12) is a reaction to the statement Since John is dead, we can now split his inheritance:

\section{(12) I hate to spoil the fun, but ${ }_{\mathrm{F}}$ he is $\left.\mathrm{NOT}\right]\left[{ }_{\mathrm{T}}\right.$ dead $]$}

With this focus-tail example, the speaker instructs the hearer to replace the record on the current locus of update-card \#17, say, for John-expressing that the value of card \#17 is dead by one saying that he is not dead. In short, the tail serves to highlight a condition on file card \#17, the one saying its value is dead. This condition is then modified in the way specified by the material in the focus.

In addition to the option of replacing a record on a file card, there is the possibility of further specifying an underspecified record, something which is assumed to be going on in the link-focus-tail example (13) given below. Suppose now that the newly appointed temp asks the executive secretary whether it was a good idea to order broccoli for the boss, and that the executive secretary gives the following answer:

\section{[t. The boss $][$ FHATES $][$ T broccoli $]$}

The idea is that the temp has an underspecified record on his card for the boss, which says that the boss has some attitude towards broccoli. The lack of information about 
the nature of this attitude is reflected by the record 'ATT', and it is this record which is replaced by 'hate' after hearing the executive secretary's answer (13):

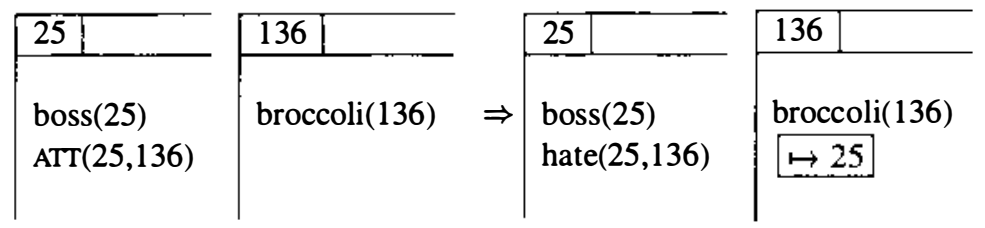

Languages choose different structural means to spell out the same informational interpretations. Vallduví studies the manifestation of information packaging in several languages, with an emphasis on Catalan and English. Cross-language comparison shows that in expressing information packaging, different languages exploit word order and prosody in various ways. Roughly speaking, English structurally realizes information packaging by means of alternative intonational contours of identical strings, whereas Catalan has a constant prosodic structure and effectuates information packaging by means of string order permutations. In fact, Vallduví argues that languages such as Catalan supply empirical support for the representation of information packaging sketched above, since these languages package their information in a much more salient way than, for example, English. Thus, while informational interpretations may be expressed exclusively by prosodic means in English, information packaging instructions in Catalan are straightforwardly reflected in syntax.

In English, the focus is associated with a $\mathrm{H}^{*}$ pitch accent (written in small caps), links are marked by a $\mathrm{L}+\mathrm{H}^{*}$ pitch accent (written in boldface), and tails are structurally characterized by being deaccented. One and the same string may be assigned different intonational phrasings in order to realize different informational interpretations. In particular, the focal pitch accent may be realized on different positions in the sentence. This is illustrated by the sentences (15), (17) and (19), construed as answers to the questions (14), (16) and (18), respectively:

(14) What did you find out about the company?

(15) [FThe boss hates BROCCOLI]

(16) What did you find out about the boss?

(17) [L The boss $][$ Fhates BROCCOLI $]$

(18) What does the boss feel about broccoli?

(19) [L The boss $][$ FHATES $][$ T broccoli $]$

In Catalan, the situation is as follows. Metaphorically speaking, one can say that Catalan focal elements remain within a so-called 'core clause', but that ground elements are 'detached' to a clause-peripheral position. In particular, links are detached to the left, and non-link ground elements undergo right-detachment. As a 
result of detaching both links and tails, the core clause (CC) is left containing only the focus of the sentence:

\section{LINKS [CC FOCUS ] TAILS}

Consider the Catalan counterparts (21), (22) and (23) of (15), (17) and (19), respectively. The all-focus sentence (21) displays the basic verb-object-subject word order. In (22) and (23), the link subject l'amo has been detached to the left. In (23), moreover, the tail direct object el bròquil has been detached to the right, leaving a clitic $(l ')$ in the focal core clause. Note that intonational structure plays a part in Catalan too, albeit 'a rather lame one' (Vallduví 1993: 33): a focal H* pitch acent is invariably associated with the last item of the core clause.

[FOdia el bròquil L'AMO]

[LL'amo][Fodia el BRÒQUIL]

[L L'amo] [FL'ODIA][Tel bróquil]

The above observations provide confirmation that information packaging involves syntax as well as prosody; hence any attempt to reduce information packaging to either syntax (for Turkish, cf. Hoffman 1995) or prosody (for English, cf. Steedman $1991,1992,1993$ ) is inadequate from a cross-linguistic point of view. ${ }^{6}$ Accordingly, Hendriks (draft) treats the range of variation in the structural realization of information packaging as displayed by Catalan and English by means of the signbased categorial grammar formalism of Hendriks (1994). Basically, this formalism is a both intonationally/syntactically and semantically/informationally interpreted version of a double 'dependency' variant (see Moortgat and Morrill 1991) of the nonassociative Lambek (1961) calculus, enriched with the unary operators of Moortgat (1994). The treatment of information packaging it accommodates differs from many of its predecessors (including other extensions of standard Lambek calculus such as Oehrle 1991, Van der Linden 1991, and Moortgat 1993), in that it does not employ focusing operators, but, instead, makes use of 'defocusing' operators that license the presence of links and tails.

Acccording to most approaches, focused constituents are semantic functors which take the non-focused part of the sentence as their argument. This analysis is based on such assumptions as made in Szabolcsi $(1981,1983)$ and Svoboda and Materna (1987), where focus is not only considered an information-packaging primitive but also an implicit truth-conditional exhaustiveness operator, and on semantic studies of the phenomenon of 'association with focus' as provided by Jacobs (1983), Rooth (1985), Krifka (1991), and others who have argued that the quantificational structure of so-called focus-sensitive operators is crucially determined by the traditional pragmatic focus-ground partition. However, Vallduví argues convincingly that 'the claim that focused constituents truth-conditionally entail exhaustiveness leads to extreme positions' (1992: 170), and Vallduví and Zacharski (1993) show that 'association with pragmatic focus' is not an inherent semantic property of 
'focus-sensitive' operators, which may express their semantics on partitions other than the focus-ground one-witness obvious cases of association with subsegments of the informational focus, with links, and with other parts of the ground.

This dissociation of the pragmatic focus-background distinction from issues of exhaustiveness and focus-sensitivity dispels the need of analyzing focused constituents as operators which semantically take scope over the non-focused parts of the sentence, which can be considered an advantage. As sentences may lack links and tails, such analyses do not immediately reflect the core status of the focus, which is the only non-optional part of a sentence. In some sense, then, all-focus sentences constitute the basic case, and the cases where there is a ground are derived from such basic all-focus structures.

\section{3. ... To Boxes}

We saw that concerning the internal structure of information states which is, in fact, crucially exploited by the different information-packaging strategies used by speakers in pursuing communicative efficiency' (1994: 7), Vallduví concludes that it is at least a system of file cards connected by Hypercard-style pointers: information packaging instructions contribute in two ways to the optimization of information update, since they provide means to designate a file card as the locus of information update and hence circumvent the redundancy of multiple update, and they identify the information of the sentence and its relation to information already present in the hearer's model.

This conclusion is challenged in Hendriks and Dekker (1996), who argue that it is begging the question: if file card systems are assumed, then the information-packaging strategies do seem to contribute to efficient information exchange. Nevertheless, the more theoretical question is whether this assumption itself is justified, and whether the organization of linguistic information exchange really presupposes such information states. After all, ushers can be very useful, but there are also halls that have unnumbered seats! For instance, files are, as Vallduví puts it, 'dimensionally richer' than the card-less discourse representation structures of Discourse Representation Theory (see Kamp 1981, Kamp and Reyle 1993), since each file card introduces its own 'representational space' where all its records are to be found while there is no sensible notion of location in discourse representation structures. Still, a hearer who employs discourse representation structures has an easier job from a bookkeeping perspective than a hearer whose information states are collections of file cards connected by pointers. Besides, one can show that given Vallduví's specific use of pointers to file cards, there is actually a one-to-one correspondence between his files and the class of discourse representation structures with atomic conditions and one marked discourse referent, the 'current locus of update'. The corresponding systems differ only in the way in which they display their information: on several cards, or in one big box. So, in a sense Vallduví's conclusion is unfalsifiable.

Moreover, it can be shown that the idea that links specify a locus of update 
in information states that are systems of file cards connected by Hypercard-style pointers is problematic for various reasons. First, it is unclear what is the locus of update for the links in [ ${ }_{\mathrm{L}}$ Every man] $\left.{ }_{\mathrm{F}} \mathrm{WALKS}\right]$, [ $\mathrm{L}$ No man] $\left.{ }_{\mathrm{F}} \mathrm{WALKS}\right]$ and ${ }_{\mathrm{L}} \mathrm{John}$ or Mary $]\left[{ }_{F}\right.$ WALKS $],{ }^{7}$ or-more in general-where and how quantified, negative and disjunctive information has to be put in the non-metaphorical file card set-up of Vallduví (1994). (Heim (1983: 184) touches on similar questions.) Second, the existence of sentences with more than one link (Vallduví (1992: 104)) raises the question what sense multiple loci of update can make that Hypercard-style pointers cannot. Third, the replacement operation triggered by the presence of tails, by itself far from unproblematic, is severely complicated by the use of file cards. And fourth, since pronouns do not necessarily induce replacement or shift the locus of update, one is forced to the counterintuitive conclusion that they form part of the focus. (The interested reader is referred to Hendriks and Dekker (1996).)

Thus, the data do not enforce the conclusion that information states have at least the structure of a collection of file cards connected by pointers. For that matter, the phenomena can also be accounted for in terms of discourse representation structures, and it is very well possible that circumventing file cards might lead to the avoidance of the complications outlined above. In view of these considerations, a card-less alternative will be defended in the present section, according to which information states are modelled by means of discourse representation structures, which are ontologically less committed than the 'dimensionally richer' file card system, in that discourse representation structures do not come with locations.

But if the use of files does not appear to be imperative, then a question must be faced: what purpose $d o$ links serve if they do not serve to specify a locus of update by ushering to locations? What does 'ushering to a location' mean if representations do not come with locations? A different perspective on the function of links is required. The perspective offered below carries less presuppositions than the file metaphor. It has its heuristic starting point in Kamp and Reyle (1993), who note that processing a plural pronoun does not always involve equating the discourse referent it introduces with one introduced earlier through the processing of some other plural NP. They consider the following example:

\section{John took Mary to Acapulco. They had a lousy time.}

Here, the plural pronoun they does not have a single NP for its antecedent. Rather, the 'antecedent' has to be 'constructed' out of various parts of the preceding text. Such examples, which are very common, seem to suggest that plural pronouns can pick up any antecedent that can be obtained from antecedent information by logical deduction. However, the deductive principles that are permitted in this context turn out to be subject to restrictions.

\section{Eight of the ten balls are in the bag. They are under the sofa.}

The pronoun they in (25) cannot be understood as referring to the two balls that are missing from the bag. Apparently, subtracting one set from another is not a permissible operation for the formation of pronominal antecedents. 
The permissible process of antecedent formation displayed by (24) is called Summation: a new discourse referent is introduced which represents the 'union' of individuals (John and Mary) and/or sets represented by discourse referents that are already part of the discourse representation structure. Other permissible processes are Abstraction, exemplified by (26), which allows the introduction of discourse referents for quantified NPs (compare also footnote 7 above), and Kind Introduction, which introduces discourse referents for a certain 'genus' explicitly mentioned in the text by a (simple or complex) noun. If they in (27) refers to the (few) men who joined the (conservative) party, we are dealing with Abstraction. The more natural reading, where they refers to men in general (and the party is presumably non-conservative), is a case of Kind Introduction.

I found every book Bill needs. They are on his desk.

Few men joined the party. They are very conservative.

In their discussion of the inferential processes available for the construction of antecedents for (plural) pronouns, Kamp and Reyle suggest the following:

What sets the admissible inference processes of Summation, Abstraction and Kind Introduction apart from an inadmissible inference pattern such as set subtraction is that the former are [... ] strictly positive (Kamp and Reyle 1993: 344), or

'cumulative' in the following sense: the newly created discourse referent represents an entity of which the discourse referents used in the application of the rule represent (atomic or non-atomic) parts. (Kamp and Reyle 1993: 394)

Notice that, when this generalization is taken in conjunction with a principle to the extent that anaphora invariably involves the addition of an equational condition ' $\mathrm{X}$ $=\mathrm{Y}^{\prime}$ ' for an anaphoric expression with discourse referent $\mathrm{Y}$ and a-possibly inferentially created-antecedent discourse referent $X$ (and such an equational approach is standard practice in Dicourse Representation Theory), the necessary result will be that anaphora is always (upward) monotone: if an expression with discourse referent $Y$ is anaphorically dependent on an expression with discourse referent $X$, then $\mathrm{X} \subseteq \mathrm{Y}$. The latter result, however, does not seem to be borne out by the facts. For example, Van Deemter (1992, 1994a) presents cases of 'non-identity anaphora' along the lines of (28), as well as minimal pairs such as (29) and (30):

(28) Our neighours are extremely nice PEOPLE.

He is $a$ TEACHER, she is a HOUSEWIFE.

John fed the ANIMALS. The cats were HUNGRY.

(30) John fed the ANIMALS. The cats were HUNGRY. 
It can be observed that the pronouns he and she are anaphorically dependent on our neighbours in (28), but that the discourse referents of the pronouns represent entities which are proper subsets of the entity represented by the discourse referent of the antecedent: obvious cases of non-monotone anaphora. Moreover, whereas the reading of (29) where the cats is anaphoric to the ANIMALS strongly and monotonously suggests that all animals fed by John were cats, the reading of (30) where the cats is anaphoric to the ANIMALS does not. It even seems to imply that John fed at least one non-cat. ${ }^{8}$ Again, we are dealing with non-monotone anaphora. Note that the texts (29) and (30) differ only in the assignment of $\mathrm{L}+\mathrm{H}^{*}$ accent to the noun phrase the cats, which is the distinguishing mark of links in English. Hence our alternative hypothesis:

Non-Monotone Anaphora Hypothesis (NAH):

Linkhood (marked by $\mathrm{L}+\mathrm{H}^{*}$ accent in English) serves to signal non-monotone anaphora. If an expression is a link, then its discourse referent $\mathrm{Y}$ is anaphoric to an antecedent discourse referent $\mathrm{X}$ such that $\mathrm{X} \nsubseteq \mathrm{Y}$.

As we will show, this hypothesis affects a range of phenomena. It subsumes not only the so-called 'non-identity' anaphora just exemplified and analyzed in Van Deemter (1992, 1994a), but also the cases of contrastive stress discussed in Rooth (1992) and Vallduví $(1992,1994)$. It contributes to an explanation of the effect of pitch accenting on pronoun referent resolution noted in Cahn (1995), Kameyama (1994), Vallduví (1994), among many others, and it sheds light on the distinction between restrictive and non-restrictive relative clauses and adjectives (see Kamp and Reyle 1993).

(a) The relationship between non-identity anaphora and linkhood can be illustrated even more saliently with relational nouns:

(32) Ten guys were playing basketball in the RAIN.

The fathers were having FUN.

(33) Ten guys were playing basketball in the RAIN.

The fathers were having FUN.

Thus, while (32) has an 'identity' reading where the fathers is anaphoric to ten guys which suggests that all ten guys playing basketball in the rain were fathers who were having fun, and (33) has a 'subsectional' reading where the fathers is anaphoric to ten guys which suggests that the fathers who were having fun constitute a proper subset of the ten basketball-playing guys, the latter text also has a-nonmonotone-'relational' reading where the fathers of the ten guys playing basketball in the rain were having fun.

Observe, by the way, that Kamp and Reyle's example (24) of Summation, a case of monotone non-identity anaphora in which the pronoun they typically apears unaccented, shows that is not so much the 'non-identity' as the 'non-monotonicity' 
of the anaphora which is responsible for the $\mathrm{L}+\mathrm{H}^{*}$ accent (that is: the linkhood) of the anaphor.

(b) According to Rooth, contrast is the cornerstone of the interpretation of focus phenomena: 'Intonational focus has a semantic import related to the intuitive notion of contrast within a set of alternative elements' (1992: 113), and Vallduví gives the following example of 'contrastive' links (1993:14):

Where can I find the cutlery?

The forks are in the CUPBOARD, but

the knives I left in the DRAWER.

However, note that contrast is not really necessary. ${ }^{9}$ Mere non-monotonicity is sufficient for $\mathrm{L}+\mathrm{H}^{*}$ accent:

Where can I find the cutlery?

The forks are in the CUPBOARD.

(c) Many authors have paid attention to the effect of pitch accenting on pronoun referent resolution. The examples below stem from Lakoff (1971).

Paul called Jim a Republican. Then he insulted him.

\section{Paul called Jim a Republican. Then he insulted him.}

For grammatical reasons (parallellism), the preferred antecedents for the unstressed pronouns he and him in (36) are Paul and Jim, respectively. The preferences are reverse for the stressed pronouns he and him in (37).$^{10}$ In the theory of Kameyama (1994), this phenomenon is accounted for as follows:

- A grammar subsystem represents the space of possibilities and a pragmatics subsystem represents the space of preferences;

- Stressed and unstressed pronouns have the same denotational range, i.e., the same range of possible values;

- Complementary Preference Hypothesis $(\mathrm{CPH})$ : A stressed pronoun takes the complementary preference of the unstressed counterpart.

Note, however, that the $N A H$ formulated in (31) actually predicts the $C P H$ effects: adding $\mathrm{L}+\mathrm{H}^{*}$ accent to pronouns means the addition of a pragmatic signal that the anaphora involved is non-monotone. In the case of singular antecedents with entityrepresenting discourse referents, this means that the anaphor does not not corefer with its antecedent. As a-surprising-consequence, we have that pronominal stress turns the grammatically determined preference for a certain antecedent into a pragmatically determined preference for non-reference with that antecedent. 
(d) The sentences (38) and (39) (taken from Kamp and Reyle 1993: 255) illustrate the familiar rule of English orthography that non-restrictive clauses are set apart from the surrounding text by commas, but that restrictive clauses are not.

(38) The son who attended a boarding school was insufferable.

(39) The son, who attended a boarding school, was insufferable.

Note that (38), in which the relative clause is used restrictively, suggests that there is more than one son, but only one who is boarding. In (39), where the relative clause is used non-restrictively, the suggestion is rather that there is only one son, of whom it is said not only that he was insufferable but also, parenthetically as it were, that he attended a boarding school. If the prosody of these sentences is taken into account, it will be clear that this pragmatic difference is in keeping with the $N A H$ as formulated in (31). Similar observations can be made with respect to the (non-)restrictiveness of the adjectives and nouns in (42) (Kamp and Reyle 1993: 372).

(40) The son who attended a boarding school was INSUFFERABLE.

(41) The son, who attended a BOARDING SCHOOL, was INSUFFERABLE.

(42) John fed the ANIMALS.

The young cats were HUNGRY.

The young cats were HUNGRY.

The young cats were HUNGRY.

The young cats were HUNGRY.

\section{Endnotes}

0 . This paper is an abridged and-somewhat-improved version of Hendriks and Dekker (1996). Most notably, a radical reduction has been applied to its second section, the part of the paper that reflects joint work of the two authors. The present author would like to thank Paul Dekker, Elisabet Engdahl, Sicb Nooteboom. Tanya Reinhart and Enric Vallduví for stimulation, cooperation and discussion.

1. Italics will be used for unaccented expressions, SMALL CAPS for expressions that bear a (focal) $\mathrm{H}^{*}$ pitch accent, and boldface for expressions that bear a $\mathrm{L}+\mathrm{H}^{*}$ pitch accent. This is the terminology of Pierrehumbert (1980) and Pierrehumbert and Hirschberg (1990). $\mathrm{H}^{*}$ accent and $\mathrm{L}+\mathrm{H}^{*}$ accent are called $\mathrm{A}$ accent and $\mathrm{B}$ accent, respectively, in Jackendoff (1972). We will assume that the relevant intonational unit for links is not the accent but rather the whole phrase, so that there is no such thing as a link-associated accent, but rather a link-associated tune.

2. The ground is also known as 'presupposition' and as 'open proposition'.

3. Subject to further syntactic and semantic restrictions, cf. footnote 7 below. 
4. Observe that to the extent that links correspond to the topic in the traditional topic/comment distinction, Vallduvi's theory is quite similar to the analysis of sentence topics presented in Reinhart (1982), where a pragmatic assertion of $\varphi$ about $a$ is formalized as $\langle a, \varphi\rangle$, in that $a$ functions as a kind of 'locus of update' for $\varphi$ (cf. below). A difference is that Reinhart allows assertions without a topic (since also $\left.\varphi \in \mathrm{PPA}_{(\mathrm{S})}\right)$ and topics that express new information.

5. The hierarchy does not imply constituency or (even) continuity. In particular, the two parts (link and tail) of the ground may not constitute a linear unit at the surface. Moreover, sentences may have more than one link, and more than one element may constitute the tail.

6. Note, moreover, that the structural realization of information packaging in Catalan involves both syntax and prosody.

7. Though 'links tend to be definite NPs' (1992: 77), Vallduví observes the 'restricted existence of indefinite links' (1992: 46). 'Sentences with quantifier links are' claimed to be 'less natural than others, causing raised eyebrows among some Catalan speakers. Sentences like $A$ tots els estudiants $s_{i}$ els $s_{i}$ donen un CARNET $t_{i}$ "To all students they give an ID" or $A$ tothom $m_{i}$ no el $_{i}$ tracten $t_{i}$ IGUAL "Everybody they don't treat the same" are extremely natural, some other sentences sound odder. Most sentences, however, are felicitous once the right context is construed, although in some cases it may require some sophistication' (Vallduví 1992: 153). Analogously, Reinhart notes that if they 'can be interpreted (pragmatically) as denoting sets, universally quantified NPs, as well as specific and generic indefinite NPs, can serve as topics' (1982: 65-66).

8. 'Strongly suggests' and 'seems to imply' instead of 'entails', since though the effects are quite strong, they are of a pragmatic, rather than a logico-semantic, nature. See also $(c)$, on pronoun referent resolution, below.

9. Nor is contrariety (as proposed in Van Deemter 1994b), witness:

Where can I find the cutlery?

The forks are in the CUPBOARD, and the knives TOO.

10. The fact that (37) insinuates that calling someone a Republican is an insult is essentially due to the de-accenting of insulted in the second sentence of (37).

\section{References}

Bosch, P., and R. van der Sandt (eds.) (1994). Focus and Natural Language Processing. Proceedings of a Conference in Celebration of the 10th Anniversary of the Journal of Semantics. Working Papers 6 (Vol. 1: Intonation and Syntax), 7 (Vol. 2: Semantics), and 8 (Vol. 3: Discourse) of the IBM Institute for Logic and Linguistics, Heidelberg.

Cahn, J. (1995). 'The Effect of Pitch Accenting on Pronoun Referent Resolution'. Manuscript. MIT, Cambridge (Mass.).

Chafe, W.L. (1976). 'Givenness, Contrastiveness, Definiteness, Subjects, Topics and Point of View'. In C.N. Li (ed.) (1976), Subject and Topic, 25-55. Associated Press, New York. 
Clark, H.H., and S.E. Haviland (1977). 'Comprehension and the Given-New Contract'. In R.O. Freedle (ed.) (1977), Discourse Production and Comprehension, 1-40. Lawrence Erlbaum Asscoicates, Hillsdale (New Jersey).

Dahl, Ö. (1974). 'Topic-Comment Structure Revisited'. In Ö. Dahl (ed.), Topic and Comment, Contextual Boundedness and Focus. Papers in Text Linguistics

6. Helmut Buske, Hamburg.

Deemter, K. van (1992). 'Towards a Generalization of Anaphora'. Journal of Semantics 9, 27-51.

Deemter, K. van (1994a). 'What's New? A Semantic Perspective on Sentence Accent'. Journal of Semantics 11, 1-31.

Deemter, K. van (1994b). 'Contrastive Stress, Contrariety and Focus'. In P. Bosch and R. van der Sandt (eds.), 39-49.

Dekker, P., and H. Hendriks (1994). 'Files in Focus'. In Engdahl (ed.), 27-38.

Engdahl, E. (ed.) (1994). Integrating Information Structure into Constraint-based and Categorial Approaches. EsPRT Basic Research Project 6852, Dynamic Interpretation of Natural Language. DYANA-2 Deliverable R1.3.B. ILLC, University of Amsterdam.

Heim, I. (1982). The Semantics of Definite and Indefinite Noun Phrases. Ph.D. Dissertation University of Massachusetts, Amherst. Published in 1989 by Garland. New York.

Heim, I. (1983). 'File Change Semantics and the Familiarity Theory of Definiteness'. In R. Bäuerle, C. Schwarze and A. von Stechow (eds.) (1983), Meaning, Use and Interpretation of Language. De Gruyter, Berlin, 164-189.

Hendriks, H. (1994). 'Information Packaging in a Categorial Perspective'. In Engdahl (ed.), 89-116.

Hendriks, H. (draft). 'Intonation, Derivation, Information'. Utrecht University.

Hendriks, H., and P. Dekker (1996). 'Links without Locations. Information Packaging and Non-Monotone Anaphora'. In P. Dekker and M. Stokhof (eds.) (1996), Proceedings of the Tenth Amsterdam Colloquium, December 1995. ILLC, University of Amsterdam.

Hoff man, B. (1995). 'Integrating "Free" Word Order Syntax and Information Structure'. Manuscript, University of Pennsylvania.

Jackendoff, R. (1972). Semantic Interpretation in Generative Grammar. MIT Press, Cambridge (Mass.).

Jacobs, J. (1983). Fokus und Skalen: Zur Syntax und Semantik von Gradpartikeln im Deutschen. Niemeyer, Tübingen.

Kameyama, M. (1994). 'Stressed and Unstressed Pronouns: Complementary Preferences'. In P. Bosch and R. van der Sandt (eds.), 475-484.

Kamp, H. (1981). 'A Theory of Truth and Semantic Representation'. In J. Groenendijk, T. Janssen and M. Stokhof (eds.) (1981), Formal Methods in the Study of Language. Mathematical Centre, Amsterdam. Reprinted in J. Groenendijk, T. Janssen and M. Stokhof (eds.) (1984), Truth, Interpretation and Information. Selected Papers from the Third Amsterdam Colloquium. Foris, Dordrecht.

Kamp, H., and U. Reyle (1993). From Discourse to Logic. Introduction to Mod- 
eltheoretic Semantics of Natural Language, Formal Logic and Discourse Representation Theory. Kluwer, Dordrecht.

Krifka, M. (1991). 'A Compositional Semantics for Multiple Focus Constructions'. Linguistische Berichte, Suppl. 4, 17-53.

Lakoff, G., (1971). 'On Generative Semantics'. In D. Steinberg and L. Jacobovitz (eds.) (1971), Semantics. Cambridge University Press, Cambridge, 232296.

Lambek, J. (1961). 'The Calculus of Syntactic Types'. In R. Jakobson (ed.) (1961), Structure of Language and its Mathematical Aspects. Providence.

Linden, E.-J. van der (1991). 'Accent Placement and Focus in Categorial Logic'. In S. Bird (ed.) (1991) Declarative Perspectives on Phonology. Edinburgh Working Papers in Cognitive Science. Eccs, Edinburgh.

Oehrle, R. (1991). 'Prosodic Constraints on Dynamic Grammatical Analysis'. In S. Bird (ed.) Declarative Perspectives on Phonology. Edinburgh Working Papers in Cognitive Science. Eccs, Edinburgh.

Moortgat, M. (1993). 'Generalized Quantifiation and Discontinuous Type Constructors'. In W. Si jtsma and A. van Horck (eds.) (1993), Proceedings of the Tilburg Symposium on Discontinuous Dependencies. De Gruyter, Berlin.

Moortgat, M. (1994). 'Residuation in Mixed Lambek Systems'. In M. Moortgat (ed.) (1994), EsPRTT Basic Research Project 6852, Dynamic Interpretation of Natural Language, DYANA-2 Deliverable R1.1.B. ILLC, University of Amsterdam, and to appear in IGPL Bulletin.

Moortgat, M., and G. Morrill (1991). 'Heads and Phrases. Type Calculus for Dependency and Constituent Structure'. OTS Research Paper, Utrecht University.

Nooteboom, S.G., and J.M.B. Terken (1982). 'What Makes Speakers Omit Pitch Accents?'. Phonetica 39, 317-336.

Pierrehumbert, J. (1980). The Phonology and Phonetics of English Intonation. Ph.D. Disertation. MIT, Cambridge (Mass.). Distributed by the IULC.

Pierrehumbert, J., and J. Hirschberg (1990). 'The Meaning of Intonational Contours in the Interpretation of Discourse'. In P. Cohen, J. Morgan and M. Pollack (eds.) (1990), Intentions in Communication. MIT Press, Cambridge (Mass.), 271-311.

Prince, E. (1981). 'Toward a Taxonomy of Given-New Information'. In P. Cole, Radical Pragmatics. Academic Press, New York, 233-255.

Reinhart, T. (1982). 'Pragmatics and Linguistics: An Analysis of Sentence Topics'. Philosophica 27, 53-94.

Rooth, M. (1985). Association with Focus. Ph.D. Dissertation University of Massachusetts, Amherst.

Rooth, M. (1992). 'A Theory of Focus Interpretation'. Natural Language Semantics 1, 75-116.

Steedman, M. (1991). 'Structure and Intonation'. Language 67, 260-296.

Steedman, M. (1992). 'Surface Structure, Intonation and "Focus"' '. In E. Klein and F. Veltman (eds.) Natural Language and Speech. Symposium Proceedings, Brussels, November 1991. Springer, Berlin.

Steedman, M. (1993). 'The Grammar of Intonation and Focus'. In P. Dekker and 
M. Stokhof (eds.) (1993), Proceedings of the Ninth Amsterdam Colloquium, December 14-17, 1993, Part III. ILLC, University of Amsterdam.

Svoboda, A., and P. Materna (1987). 'Functional Sentence Perspective and Intensional Logic'. In R. Dirven and V. Fried (eds.) Functionalism in Linguistics. John Benjamins, Amsterdam.

Szabolcsi, A. (1981). 'The Semantics of Topic-Focus Articulation'. In J. Groenendijk, T. Janssen and M. Stokhof (eds.) (1981), Formal Methods in the Study of Language. Mathematical Centre, Amsterdam.

Szabolcsi, A. (1983). 'Focussing Properties, or the Trap of First Order'. In Theoretical Linguistics 10, 125-145.

Vallduví, E. (1992). The Informational Component. Garland, New York.

Vallduví, E. (1993). 'Information Packaging: A Survey'. Report prepared for Word Order, Prosody, and Information Structure. Centre for Cognitive Science and Human Communication Research Centre, University of Edinburgh.

Vallduví, E. (1994). 'The Dynamics of Information Packaging'. In Engdahl (ed.), $1-27$.

Vallduví, E., and R. Zacharski (1993). 'Accenting Phenomena, Association with Focus, and the Recursiveness of Focus-Ground'. InP. Dekker and M. Stokhof (eds.) (1993) Proceedings of the Ninth Amsterdam Colloquium, December 1993, Part III. ILLC, University of Amsterdam. 